\title{
Perceptions and Practices towards Medication Non-Adherence among Hypertensive Patients: An Observational Study
}

Muhammad N. Khan ${ }^{1}$, Najia Soomro ${ }^{2}$, Tariq Ashraf ${ }^{3}$, Khalid Naseeb ${ }^{3}$, Rajesh Kumar ${ }^{3}$, Usman Bhatti 3 , Syed Taha Ali ${ }^{3}$, Musa Karim ${ }^{4}$

1. Interventional Cardiology, National Institute of Cardiovascular Diseases (NICVD), Karachi, PAK 2. Cardiology, Liaquat National Hospital, Karachi, PAK 3. Cardiology, National Institute of Cardiovascular Diseases (NICVD), Karachi, PAK 4. Department of Biostatistics, National Institute of Cardiovascular Diseases (NICVD), Karachi, PAK

Corresponding author: Muhammad N. Khan, muhammad.nauman@nicvd.org

\section{Abstract \\ Background}

The present study broadly evaluates the adherence to pharmacotherapy, perceptions, and practices among ambulatory hypertensive patients attending a cardiac institution in Karachi, Pakistan.

\section{Methods}

A cross-sectional, single-center study was conducted at the National Institute of Cardiovascular Diseases Karachi, Pakistan. The study continued from 4 July 2019 to 3 September 2019. A total of 200 patients with a primary diagnosis of hypertension (HTN) were recruited for the study. The data was collected through a questionnaire based on a nine-item modified adherence predictor scale to assess medication adherence. Along with the demographic details patients smoking status, history of comorbidities and past complications were noted.

\section{Results}

It was found that the mean age of the study population was $56.45 \pm 12.36$ years. A total of $62.5 \%$ of patients were taking medication daily while $15.5 \%$ were consuming medications intermittently and only $6.5 \%$ patients were not adherent at all. Around $35 \%$ patients preferred follow-up visits once in a month. Besides this, $35.5 \%$ patients never monitored their blood pressure while more than half of the studied population believed that their BP has mostly been controlled and skipped the prescribed medication.

\section{Conclusion}

The study indicated that the perception and awareness among the hypertensive patients regarding their medical condition are suboptimal. Concerted strategies like health education program and campaigns must

Received 09/30/2019

Review began 09/30/2019 Review ended 10/08/2019 Published 10/15/2019

\section{() Copyright 2019}

Khan et al. This is an open access article distributed under the terms of the Creative Commons Attribution License CC-BY 3.0., which permits unrestricted use, distribution, and reproduction in any medium, provided the original author and source are credited.
Categories: Cardiology

Keywords: non-adherence, hypertension, blood pressure, perceptions, medication

\section{Introduction}

Hypertension (HTN) is one of the major attributable risk for the cardiovascular morbidity and mortality and hence it makes up more than half of the global disease burden causing numerous premature deaths per annum [1-2]. Research studies indicate that blood pressure (BP) management helps to reduce the disease intensity and risk of other comorbidities like stroke, renal disease, heart failure, and death [3-4]. Moreover, the disease risk and associated death ratio are more commonly observed in low to middle-income countries, with increased prevalence among individuals having lower socioeconomic statuses [5-6]. According to the estimates provided by the World Health Organization (WHO), each year about 17.3 million lives are carried away by cardiovascular diseases and by 2030 it is predicted that the rate might increase to 23 million [7]. Also, one-quarter of the adult population is affected by this chronic non-communicable disease worldwide. Pakistan being on top of the list contributing $50 \%$ of the affectees to this global burden, being a developing state with compromised healthcare facilities the diagnosis and treatment of such health risks are infrequent $[7]$.

Among numerous influencers those are associated with HTN, advancing age is one of the most significant non-modifiable risk factor [8]. However, gender is another lead with greater susceptibility in men at an early age while in women, developing HTN is more after the age of 60 years [9]. Followed by race as the other influencer to increase the risk of HTN with reported higher prevalence among the black population when compared to white with mechanism still unknown. Other than that, there can be an influence of family 
disposition, decreased physical activity, increased weight, smoking, alcohol consumption as well as the precipitating influence of dietary factors such as high sodium, low potassium, and decreased Vitamin D consumption. Among the serious complexities' cholesterol, diabetes, sleep apnea, and kidney diseases might play the role of triggering factors.

Even though the field of medication has advanced and flourished rapidly, still HTN is poorly controlled among the diagnosed patients [10]. It may be due to poor medication adherence, non-compliance with follow-up visits, and lifestyle modifications [10]. Medication non-adherence is the prime difficulty that must be identified and addressed in each case. Around $50 \%$ of the patients suffering from chronic illnesses are adherent to antihypertensive medications prescribed by the healthcare provider [11]. It is recommended that moderating the salt and fat intake, regular exercising, reducing stress as well as quitting the habits of alcohol consumption and smoking can keep BP quite under optimal range [12-13]. Furthermore, it also reduces the risk of having a stroke, myocardial infarction, or heart failure [14]. For treatment adherence and long-term effectiveness, self-management is necessary along with the self-information of the patient about their clinical condition that should be well understood by the patient and assessed regularly [15]. Though due to long-term morbidity, the patient can develop coping skills to combat the disease more appropriately with active involvement in disease handling, which is a progressive approach [16].

Therefore, lifestyle modification and treatment adherence are the two prime factors that must be keenly planned for the effective management of HTN [10]. The primary aim of the study was to evaluate medication adherence and the contributing factors of HTN along with the assessment of common perceptions and practices related to its management.

\section{Materials And Methods}

This cross-sectional, single center study was conducted at the cardiology clinic of tertiary care hospital, National Institute of Cardiovascular Diseases Karachi, Pakistan. The study continued for a period of three months from 4 July 2019 to 3 September 2019. A total of 200 patients with a primary diagnosis of HTN were recruited for the study. Patients on antihypertensive medications for at least three months were enrolled irrespective of the gender using consecutive sampling technique. While patients under hypertensive emergency with BP > 180/110 mmHg or those with acute coronary syndrome, acute stroke, hypertensive encephalopathy, aortic dissection, or acute kidney injury, uncontrolled psychiatric disorder (schizophrenia or major depression), stage $\mathrm{V}$ chronic kidney disease (CKD) or end-stage renal disease (glomerular filtration rate $<15 \mathrm{ml} / \mathrm{min} / 1.73 \mathrm{~m}^{2}$ ) were excluded. Moreover, patients with a history of active substance abuse, patients who refused to take medications, and pregnant female patients were excluded from the study sample.

The data were collected through a questionnaire based on components of the nine-item modified Morisky Adherence Predictor Scale (MMAPS), to assess medication adherence, patients' practices, and perception about HTN and BP outcomes [17]. HTN status was marked as controlled and uncontrolled BP. Systolic blood pressure (SBP) $>140$ or diastolic blood pressure (DBP) $>90$ was considered as uncontrolled BP, else it was considered as controlled. The patient demographic details were collected along with smoking status, history of comorbidities such as obesity, diabetes, and high cholesterol and history of past complications like stroke, kidney failure, visual problem, and heart attack or failure.

Before administering the study questionnaire, informed consent was obtained from each patient (both in Urdu and English). All conducts were performed ethically in accordance with the International Conference on Harmonization - Good Clinical Practice (ICH-GCP) guidelines and the ethical approval was received from the Ethical Review Committee of National Institute of Cardiovascular Diseases (Ref. No. ERC-39/2019) prior to the study.

The collected data were analyzed using International Business Machines Statistical Package for the Social Sciences (IBM SPSS), Version 21.0, qualitative data were summarized as frequency and percentage while mean \pm standard deviation was used for quantitative data. The association of gender, smoking status, education, comorbidities, and past complications with the HTN status was evaluated through the Chi-square test. Mann-Whitney U-test was used to assess the relationship between patient's practices, perception, and HTN status where $p$ value $<0.05$ was considered significant.

\section{Results}

A total of 200 patients fulfilling the eligibility criteria and provided consent. Out of which 124 were males and 76 were females. The mean age of the study participants was $56.45 \pm 12.36$ years with a mean duration of HTN $5.80 \pm 6.43$ years (Table 1). The clinical and personal history was also recorded, i.e., 85 out of the total were smokers, 143 had a sedentary lifestyle, and 76 were overweight. The information regarding comorbidities was also taken and it was found that 122 patients were diabetic, 154 with high cholesterol, 140 reported visual problems, and 169 had the previous history of heart attack/failure. Based on the criteria mentioned in the above methodology, 73 out of 200 patients were observed with controlled BP while 127 had uncontrolled BP (Table 1). 


\section{Cureus}

\begin{tabular}{|c|c|c|}
\hline Variables & Sub-categories & $(n=200)$ \\
\hline Age (Years) & & $56.45 \pm 12.36$ \\
\hline Duration of HTN (Years) & & $5.80 \pm 6.43$ \\
\hline SBP (mmHg) & & $150 \pm 27.99$ \\
\hline DBP (mmHg) & & $85.70 \pm 12.74$ \\
\hline \multirow{2}{*}{ Gender } & Male & $124(62.0)$ \\
\hline & Female & $76(38.0)$ \\
\hline \multirow{6}{*}{ Education } & No Education & $87(43.5)$ \\
\hline & Primary & $38(19.0)$ \\
\hline & Secondary (Metric) & $40(20.0)$ \\
\hline & Intermediate & $13(6.5)$ \\
\hline & Bachelors & $17(8.5)$ \\
\hline & Masters & $5(2.5)$ \\
\hline \multirow{2}{*}{ Smoker } & Yes & $85(42.5)$ \\
\hline & No & $115(57.5)$ \\
\hline \multirow{2}{*}{ HTN Status } & Controlled BP & $73(36.5)$ \\
\hline & Uncontrolled BP & 127(63.5) \\
\hline \multirow{2}{*}{ Lifestyle } & Active & $57(28.5)$ \\
\hline & Sedentary & $143(71.5)$ \\
\hline \multirow{3}{*}{ BMI Index } & Underweight & $5(2.5)$ \\
\hline & Normal & 119(59.5) \\
\hline & Over weight & $76(38)$ \\
\hline \multirow{6}{*}{ Other chronic illnesses } & Diabetes & 122(61.0) \\
\hline & High Cholesterol & $154(77.0)$ \\
\hline & Stroke & $17(8.5)$ \\
\hline & Kidney failure & $26(13.0)$ \\
\hline & Visual problem & $140(70.0)$ \\
\hline & Heart attack/failure & $169(84.5)$ \\
\hline
\end{tabular}

\section{TABLE 1: Demographics and clinical characteristics of the study population}

*BP: Blood Pressure; HTN: Hypertension; SBP: Systolic Blood Pressure; DBP: Diastolic Blood; BMI: Body Mass Index

${ }^{*}$ Quantitative data were presented with mean \pm standard deviation; Qualitative data were presented with frequency and percentage.

According to the results in Table 2, 62.90\% (78/124) of males and 64.47\% (49/76) of females were having uncontrolled BP, out of 127 patients from the uncontrolled BP group $40.15 \%$ were smokers while $46.67 \%$ of the 73 patients in controlled BP group were smokers. A significant association was observed between obesity and HTN status ( $\mathrm{p}<0.05)$, and $65.79 \%(50 / 76)$ overweight patients were having controlled BP. Similarly, diabetes and visual problems also had a significant association with HTN status. Moreover, increased comorbidities were observed among the patients having uncontrolled BP. 


\section{Cureus}

\begin{tabular}{|c|c|c|c|c|}
\hline \multirow{2}{*}{ Variables } & \multirow{2}{*}{ Sub-category } & \multicolumn{2}{|l|}{ HTN status } & \multirow{2}{*}{ P-value } \\
\hline & & Controlled ( $n=73)$ & Uncontrolled $(n=127)$ & \\
\hline \multirow{2}{*}{ Gender } & Male & $46(63.01)$ & $78(61.4)$ & \multirow{2}{*}{0.823} \\
\hline & Female & $27(36.9)$ & $49(38.58)$ & \\
\hline \multirow{2}{*}{ Smoking Status } & Smoker & $34(46.57)$ & $51(40.15)$ & \multirow{2}{*}{0.377} \\
\hline & Non-smoker & $39(53.42)$ & $76(59.84)$ & \\
\hline \multirow{3}{*}{ BMI Index } & Underweight & $5(6.84)$ & $0(0)$ & \multirow{3}{*}{0.023} \\
\hline & Normal & $42(57.53)$ & $77(60.62)$ & \\
\hline & Over weight & $26(35.61)$ & $50(39.37)$ & \\
\hline \multirow{6}{*}{ Other Chronic Illnesses } & Diabetes & $37(50.68)$ & 85(66.92) & 0.023 \\
\hline & High cholesterol & $58(79.45)$ & $96(75.59)$ & 0.532 \\
\hline & Stroke & $6(8.21)$ & $10(7.87)$ & 0.894 \\
\hline & Kidney failure & $10(13.69)$ & $16(12.59)$ & 0.824 \\
\hline & Visual problem & $41(56.16)$ & 99(77.95) & 0.001 \\
\hline & Heart attack/failure & 60(82.19) & 109(85.82) & 0.874 \\
\hline \multirow{2}{*}{ Life style } & Sedentary & $51(69.86)$ & $92(72.44)$ & \multirow{2}{*}{0.697} \\
\hline & Active & $22(30.13)$ & $35(27.55)$ & \\
\hline
\end{tabular}

TABLE 2: Association of hypertension status with sociodemographic characteristics of the study population

*BP: Blood pressure; BMI: Body Mass Index

${ }^{*} \mathrm{SBP}>130$ or $\mathrm{DBP}>80$ was considered as uncontrolled BP;

*Chi-square was applied; $p$ value $<0.05$ was considered significant.

Participants' perceptions and practices regarding their hypertensive illness showed that 125/200 were taking medication daily while 13/200 were those who never took prescribed medication. Follow-up frequency was also monitored, 70/200 preferred follow-up visit once per month while 71/200 never went for a follow-up visit. BP monitoring frequency was also recorded 20/200 monitored BP daily while 71/200 never monitored their BP. 100/200 believed that BP is mostly controlled and 40 disagreed to the point moreover, $64 / 200$ agreed that BP medication is necessary while 25/200 disagreed (Table 3). 


\section{Cureus}

\begin{tabular}{|c|c|c|}
\hline Variables & Sub-categories & $n(\%)$ \\
\hline \multirow{4}{*}{ Medication Intake } & Everyday & $125(62.5)$ \\
\hline & Most of the days & $31(15.5)$ \\
\hline & Some of the days & $31(15.5)$ \\
\hline & Never & $13(6.5)$ \\
\hline \multirow{5}{*}{ Follow-up Visits } & Multiple times in a month & $11(5.5)$ \\
\hline & Once in a month & $70(35.0)$ \\
\hline & Once every 6 months & $21(10.5)$ \\
\hline & Once a year & 27 (13.5) \\
\hline & Never & $71(35.5)$ \\
\hline \multirow{5}{*}{ BP Monitoring Frequency } & Everyday & $20(10.0)$ \\
\hline & Every $2-3$ days & $40(20.0)$ \\
\hline & Once a week & $22(11.0)$ \\
\hline & Once a month & 47 (23.5) \\
\hline & Never & $71(35.5)$ \\
\hline \multirow{5}{*}{$\mathrm{BP}$ is mostly controlled } & Strongly agree & $4(2.0)$ \\
\hline & Agree & $100(50.0)$ \\
\hline & Uncertain & $41(20.5)$ \\
\hline & Disagree & $40(20.0)$ \\
\hline & Strongly disagree & $15(7.5)$ \\
\hline \multirow{5}{*}{ BP medication is necessary } & Strongly agree & $55(27.5)$ \\
\hline & Agree & $64(32.0)$ \\
\hline & Uncertain & $43(21.5)$ \\
\hline & Disagree & 25 (12.5) \\
\hline & Strongly disagree & $13(6.5)$ \\
\hline
\end{tabular}

TABLE 3: Perceptions and practices of hypertensive patients regarding blood pressure management

*BP: Blood pressure

There was a significant association observed between medication intake frequency and HTN status ( $<<0.05)$. Moreover, it was also significantly associated with perceptions of hypertensive patients related to the illness. Perceptions like BP is mostly controlled and BP medication necessity was also positively associated $(\mathrm{p}<0.05)$ (Table 4). 


\section{Cureus}

\begin{tabular}{|c|c|c|c|}
\hline \multirow{2}{*}{ Variables } & \multicolumn{2}{|c|}{ HTN Status Mean Rank } & \multirow{2}{*}{ P-value } \\
\hline & Controlled & Uncontrolled & \\
\hline Medication Intake Frequency & 137.19 & 79.41 & 0.000 \\
\hline Follow up visit Frequency & 99.58 & 101.03 & 0.857 \\
\hline BP monitoring Frequency & 109.84 & 95.13 & 0.073 \\
\hline $\mathrm{BP}$ is mostly controlled & 113.18 & 93.21 & 0.011 \\
\hline BP medication is necessary & 137.84 & 79.04 & 0.000 \\
\hline
\end{tabular}

\section{TABLE 4: Patients' practices and perception in relation to hypertension status}

*HTN: Hypertension; BP: Blood pressure

*Mann-Whitney U-test was applied keeping P-value $<0.05$ as statistically significant cutoff

No association was observed between medication adherence and the educational level of the patient. The association of medication adherence status with educational level of the patient is presented in Table 5 .

\begin{tabular}{|c|c|c|c|c|}
\hline \multirow{2}{*}{ Educational Level } & \multirow{2}{*}{ Base [N] } & \multicolumn{2}{|c|}{ Medication Adherence Rate } & \multirow{2}{*}{ P-value } \\
\hline & & Non-adherent & Adherent & \\
\hline Illiterate & 87 & 18(20.69) & 69(79.31) & \multirow{4}{*}{0.958} \\
\hline Primary & 38 & $8(21.05)$ & $30(78.95)$ & \\
\hline Secondary to intermediate & 53 & 13(24.53) & $40(75.47)$ & \\
\hline Bachelors or higher & 22 & $5(22.73)$ & 17(77.27) & \\
\hline
\end{tabular}

TABLE 5: Association of medication adherence status with the educational level of patient

Non-adherent = "some of the days" or "never"

Adherent = "every day" or "most of the days"

${ }^{*}$ Chi-square was applied; P-value $<0.05$ was considered significant

\section{Discussion}

The current study provides several important insights into the perceptions and practices of the patients towards HTN management. The major recognizable features associated with uncontrolled HTN were gender, smoking, marital status, diabetes, medication adherence, etc. It is a known fact that lack of treatment adherence leads to increased hypertensive severity and boosts the mortality rate [18]. An optimal medication intake frequency was observed in the study sample, $62.5 \%$ of patients were taking medication daily while 15.5\% showed intermittent adherence and 6.5\% never took the prescribed medication (Table 3). It is evident that following the prescribed treatment regime and attending the follow-up visits results in improved health outcomes and decreases the overall healthcare costs [19-20]. According to the previous literature more than half of the hypertensive patients discontinue medication roughly a year after initiation [21]. The most highlighted factor found in association with the treatment non-adherence are the side-effects of the medication [12].

Though it has been revealed that low literacy rate is one of the leading aspects behind poor treatment adherence [22]. But according to our findings, most of the HTN patients enrolled in the study were adherent to medication (Table 3), which in comparison to their educational status was contradictory as many of them had below-average literacy rate (Table 5). Around $43.5 \%$ were illiterate while only $20 \%$ had passed the secondary education (Table 1). Several unintentional reasons such as forgetfulness, decreased health literacy, lack of symptoms and carelessness are also associated with medication non-adherence [23]. Hence, it is the prime responsibility of the healthcare providers to prevent non-adherence either through reflective 
listening or by considering the patient's psychosocial and medical requirements keeping personal opinions aside.

A significant association was observed between medication adherence and HTN status (Table 4), as other parallel studies also specified a direct relationship between treatment adherence and outcomes of HTN [24]. Research indicates that the patient's perception and behaviors are dependent upon their belief regarding disease susceptibility, disease severity and the benefits they are willing to attain [25]. Our results showed that more than half of the population agreed that BP medication is necessary (Table 2). Likewise, another study reported that $90 \%$ patients believed antihypertensive medications were necessary to keep their BP under normal range, while there were a few who believed that it is a benign illness and no therapeutic help is required for recovery [19]. Despite being diagnosed with high BP, more than $70 \%$ of the Asian hypertensive patients have uncontrolled BP [26]. Reluctance and negative perceptions have taken over the disease management rate. Around 50\% of the study patients believed that their BP is mostly controlled and this negative perception holds a significant impact on HTN status $(\mathrm{p}<0.05)$ (Tables 3 and 4).

It was observed that $5.5 \%$ patients visited the healthcare provider for follow-up multiple times in a year, 13.5\% preferred follow-up visit once in a year while 35.5\% patients never went for the follow-up visits (Table 3). Follow-up visits have the utmost importance in the life of hypertensive patients, the risk of multimorbidity and mortality increases due to the untracked visit-to-visit variability (VVV) of BP [27]. Secondary to the follow-up frequency, BP monitoring frequency was also observed, $35.5 \%$ of patients never monitored their BP while only 10\% were consistently monitoring their BP (Table 3). Moreover, no significant association was observed between the monitoring frequency and HTN status ( $\mathrm{p}=0.073$ ) (Table 4). Similarly, Ramón and his colleagues concluded in their study that the mean BP values are linked with the duration of measurement as compared to the frequency of measurement [28].

According to the National Institute of Diabetes and Digestive and Kidney Diseases Health Information Center, increased weight leads to numerous health problems mainly associated with heart [29]. BMI holds significant association with the HTN status either controlled or uncontrolled, 39.37\% overweight patients had uncontrolled BP (Table 2). Centers for Disease Control and Prevention (CDC) report states regarding obesity and BP states that increased weight intensifies the risk of high BP disposing an individual to several other co-morbidities.

Our study explored medication adherence, perceptions, and practices among hypertensive patients. There are few limitations associated with it, first and the most significant is self-reporting of medication adherence, although MMAPS was used to assess compliance, other is the high prevalence of diabetes and coronary artery disease which may be overestimated as most of these patients have multiple comorbid conditions. Moreover, it was a uni-center study, the sample was limited to a single tertiary healthcare center only. There could be a more pronounced display of patient's perception and practices regarding the illness. Therefore, further research is required to explore other associated factors with HTN to fill gaps in the existing literature.

\section{Conclusions}

This study explored the association of negative perception regarding controlled BP and HTN status. Majority of the patients believed that antihypertensive medication is necessary for effective BP control. It is suggested that treatment adherence education and counseling for hypertensive patients are necessary in order to ensure improved BP control and therapeutic outcomes.

\section{Additional Information \\ Disclosures}

Human subjects: Consent was obtained by all participants in this study. National Institute of Cardiovascular Diseases Karachi issued approval ERC-39/2019. Ethical approval was received from the Ethical Review Committee of National Institute of Cardiovascular Diseases (Ref. No. ERC-39/2019) prior to the study. Animal subjects: All authors have confirmed that this study did not involve animal subjects or tissue. Conflicts of interest: In compliance with the ICMJE uniform disclosure form, all authors declare the following: Payment/services info: All authors have declared that no financial support was received from any organization for the submitted work. Financial relationships: All authors have declared that they have no financial relationships at present or within the previous three years with any organizations that might have an interest in the submitted work. Other relationships: All authors have declared that there are no other relationships or activities that could appear to have influenced the submitted work.

\section{Acknowledgements}

Authors are thankful to Ali Moazzam and Sonia Bashir, heart failure and study coordinators. The authors wish to acknowledge the support of Medical Affairs department of Getz Pharma for providing technical support in terms of manuscript editing and formatting. 


\section{References}

1. Whitworth JA: World Health Organization, International Society of Hypertension Writing Group, WHO-ISH statement on management of hypertension. J Hypertens. 2003, 21:1983-1992. 10.1097/00004872200311000-00002

2. Global status report on noncommunicable diseases 2010 . (2011). Accessed: 15 July 2019: https://www.who.int/nmh/publications/ncd_report2010/en/.

3. Sundström J, Arima H, Woodward M, et al.: Blood pressure-lowering treatment based on cardiovascular risk: a meta-analysis of individual patient data. Lancet. 2014, 384:591-8. 10.1016/S0140-6736(14)61212-5

4. Sundstrom J, Arima H, Jackson R, et al.: Effects of blood pressure reduction in mild hypertension: a systematic review and meta-analysis. Ann Intern Med. 2015, 162:184-191. 10.7326/M14-0773

5. Dzudie A, Kengne AP, Muna WF, et al.: Prevalence, awareness, treatment and control of hypertension in a self-selected sub-Saharan African urban population: a cross-sectional study. BMJ Open. 2012, 2:001217. 10.1136/bmjopen-2012-001217

6. Hendriks ME, Wit FW, Roos MT, et al.: Hypertension in sub-Saharan Africa: cross-sectional surveys in four rural and urban communities. PloS One. 2012, 7:32638. 10.1371/journal.pone.0032638

7. 50\% of adults in Pakistan are suffering from hypertension . (2018). Accessed: 1 July 2019: https://dailytimes.com.pk/241133/50-of-adults-in-pakistan-are-suffering-from-hypertension/.

8. Soubeiga JK, Millogo T, Bicaba BW, Doulougou B, Kouanda S: Prevalence and factors associated with hypertension in Burkina Faso: a countrywide cross-sectional study. BMC Public Health. 2017, 17:64. 10.1186/s12889-016-3926-8

9. Cutler JA, Sorlie PD, Wolz M, Thom T, Fields LE, Roccella EJ: Trends in hypertension prevalence, awareness, treatment, and control rates in United States adults between 1988-1994 and 1999-2004. Hypertension. 2008, 52:818-827. 10.1161/HYPERTENSIONAHA.108.113357

10. Akpa MR, Alasia DD, Emem-Chioma PC: An appraisal of hospital based blood pressure control in Port Harcourt Nigeria. Niger Health J. 2008, 8:27-30.

11. Haynes RB, McDonald HP, Garg A: Interventions for helping patients to follow prescriptions for medications. Cochrane Database Syst Rev. 2002, 2:000011. 10.1002/14651858.CD000011

12. Svetkey LP, Erlinger TP, Vollmer WM, et al.: Effect of lifestyle modifications on blood pressure by race, sex, hypertension status, and age. J Hum Hypertens. 2005, 19:21-31. 10.1038/sj.jhh.1001770

13. Xin X, He J, Frontini MG, Ogden LG, Motsamai OI, Whelton PK: Effects of alcohol reduction on blood pressure a meta-analysis of randomized controlled trails. Hypertension. 2001, 38:1112-17. 10.1161/hy1101.093424

14. Neal B: Blood Pressure Lowering Treatment Trialists' Collaboration: Effects of ACE inhibitors, calcium antagonists, and other blood-pressure-lowering drugs: results of prospectively designed overviews of randomised trials. Blood Pressure Lowering Treatment Trialists' Collaboration. Lancet. 2000, 356:1955-64.

15. Lorig KR, Holman H: Self-management education: history, definition, outcomes, and mechanisms . Ann Behav Med. 2003, 26:1-7. 10.1207/S15324796ABM2601 01

16. Bodenheimer T, Lorig K, Holman H, Grumbach K: Patient self-management of chronic disease in primary care. JAMA. 2002, 288:2469-75. 10.1001/jama.288.19.2469

17. Voils CI, Hoyle RH, Thorpe CT, Maciejewski ML, Yancy Jr WS: Improving the measurement of self-reported medication nonadherence. J Clin Epidemiol. 2011, 64:250-54. 10.1016/j.jclinepi.2010.07.014

18. Adisa R, Ilesanmi OA, Fakeye TO: Treatment adherence and blood pressure outcome among hypertensive out-patients in two tertiary hospitals in Sokoto, Northwestern Nigeria. BMC cardiovascular disorders. 2018, 18:194. 10.1186/s12872-018-0934-x

19. DiMatteo MR, Giordani PJ, Lepper HS, Croghan TW: Patient adherence and medical treatment outcomes: a meta-analysis. Med Care. 2002, 40:794-811. 10.1097/00005650-200209000-00009

20. Nasseh K, Frazee SG, Visaria J, Vlahiotis A, Tian Y: Cost of medication nonadherence associated with diabetes, hypertension, and dyslipidemia. Am J Pharm Benefits. 2012, 4:41-7.

21. Vrijens B, Vincze G, Kristanto P, Urquhart J, Burnier M: Adherence to prescribed antihypertensive drug treatments: longitudinal study of electronically compiled dosing histories. BMJ. 2008, 336:1114-17. 10.1136/bmj.39553.670231.25

22. Adekoya-Cole TO, Akinmokun OI, Enweluzo GO, Badmus OO, Alabi EO: Poor health literacy in Nigeria: causes, consequences and measures to improve it.. Nig Q J Hosp Med. 2015, 25:112-7.

23. Meinema JG, van Dijk N, Beune EJ, Jaarsma DA, van Weert HC, Haafkens JA: Determinants of adherence to treatment in hypertensive patients of African descent and the role of culturally appropriate education. PLoS One. 2015, 10:0133560. 10.1371/journal.pone.0133560

24. Krousel-Wood M, Thomas S, Muntner P, Morisky D: Medication adherence: a key factor in achieving blood pressure control and good clinical outcomes in hypertensive patients. Curr Opin Cardiol. 2004, 19:357-62. 10.1097/01.hco.0000126978.03828.9e

25. AlHewiti A: Adherence to long-term therapies and beliefs about medications . Int J Family Med. 2014, 2014:479596. 10.1155/2014/479596

26. Wu Y, Tai ES, Heng D, Tan CE, Low LP, Lee J: Risk factors associated with hypertension awareness, treatment, and control in a multi-ethnic Asian population. J Hypertens. 2009, 27:190-7. 10.1097/hjh.0b013e328317c8c3

27. Muntner P, Whittle J, Lynch AI, et al.: Visit-to-visit variability of blood pressure and coronary heart disease, stroke, heart failure, and mortality: a cohort study. Ann Intern Med. 2015, 163:329-38. 10.7326/M14-2803

28. Hermida RC, Ayala DE, Fernandez JR, Mojon A, Calvo C: Influence of measurement duration and frequency on ambulatory blood pressure monitoring. Rev Esp Cardiol. 2007, 60:131-8. 10.1016/S1885-5857(07)60125-X

29. Health Risks of Being Overweight. (2015). Accessed: 1 July 2019: https://www.niddk.nih.gov/healthinformation/weight-management/health-risks-overweight. 